\title{
A low complexity RF based sensor array for lung disease detection using inkjet printing
}

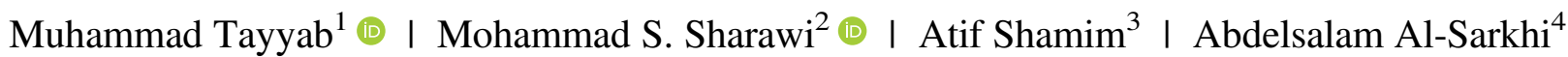

${ }^{1}$ Huawei Technologies Finland Oy, Helsinki, Finland

${ }^{2}$ Department of Electrical Engineering, King Fahd University for Petroleum and Minerals (KFUPM), Dhahran, Saudi Arabia

${ }^{3}$ Department of Electrical Engineering, King Abdullah University of Science and Technology (KAUST), Thuwal, Saudi Arabia

${ }^{4}$ Mechanical Engineering Department, King Fahd University for Petroleum and Minerals (KFUPM), Dhahran, Saudi Arabia

\section{Correspondence}

Mohammad S. Sharawi, Department of Electrical Engineering, King Fahd University for Petroleum and Minerals (KFUPM), Dhahran 31261, Saudi Arabia.

Email: msharawi@kfupm.edu.sa

\section{Funding information}

King Abdullah University of Science and Technology; KFUPM-KAUST, Grant/Award Number: KAUST-002; National Plan for Science, Technology and Innovation (Maarifah)—King Abdulaziz City for Science and Technologythrough the Science and Technology Unit at King Fahd University of Petroleum and Minerals (KFUPM) - the Kingdom of Saudi Arabia, Grant/ Award Number: 15-MED-3742-04

\begin{abstract}
This article presents the design of a low complexity, low power, small-sized, wearable, inkjet printed, cheap, and noninvasive radio frequency (RF) based sensor array for pulmonary edema and emphysema condition monitoring inside the patient chest. The RF sensor consists of 38 electrodes and 37 ports. The size of the sensor is $4 \mathrm{~cm} \times 89.4 \mathrm{~cm}$ to cover the chest of an average adult. The sensor is optimized to operate at $60 \mathrm{MHz}$. The scattering coefficients $S_{\mathrm{i} 1}$ are measured at each passive port and then the Least Squares (LS) method is used to form an equation for average dielectric constant estimation. The dielectric constant estimation method is used to detect the presence of water/air in human and porcine lungs. The average measured dielectric constants of normal human lung tissue, edema, and emphysema infected lungs are estimated with errors of $3.54 \%, 4.83 \%$, and $4 \%$, respectively. The porcine lung tissue-mimicking phantom with proper electrical properties is formed using a water and salt $(\mathrm{NaCl})$ mixture. To detect the different stages of pulmonary edema, $200 \mathrm{~mL}$ water balls are inserted in the inner layer of the chest model. The measured errors were $2.68 \%, 0.87 \%, 2.18 \%$, and $2.8 \%$ for normal porcine lung, adding 6 water balls, adding 12 water balls, and adding 18 water balls, respectively.
\end{abstract}

\section{KEYWORDS}

dielectric constant, inkjet printing, least square method, pulmonary edema, pulmonary emphysema, RF sensor

\section{1 | INTRODUCTION}

The traditional methods of noninvasive imaging in the medical field are the magnetic resonance imaging (MRI), computed tomography (CT), and X-rays. These methods are expensive and require heavy equipment. The frequent use of CT and X-rays methods will affect the patients' health due to radiation exposure. Unattended and uninterrupted monitoring of a patient health is an essential requirement in some medical devices. Some commercially available devices can monitor respiration rate, temperature and heart rate. ${ }^{1,2}$ Using the Doppler Effect, printed antennas for body wearable applications were used for remote detection of respiration and heartbeat in Ref. 1. Other wearable health monitoring devices are also available, but they cannot monitor deep tissue changes and many of them are very expensive. A low- cost, wearable sensor capable of continuously monitoring a patient condition (ie, deep tissue conditions) is of great importance in the medical field.

The traditional methods for noninvasive imaging of deep tissues within the body have many disadvantages such as unsuitability for continuous time monitoring, need for regular hospital visits, expensive, difficult to carry due to large and heavy equipment, and side effects due to radiation exposure if frequently used. ${ }^{2}$ Wearable and continuous health monitoring sensors are discussed in Refs. 2,3. These are limited for monitoring breathing, heart rate and skin temperature only. These sensors have advancements in data collection but they lack deep tissue monitoring.

Noninvasive imaging techniques include electrical impedance tomography (EIT), ultrasound impedance tomography and microwave imaging. ${ }^{4}$ By measuring the voltages 
and currents on the periphery of a body, EIT reconstructs the spatial conductivity and permittivity within the body. ${ }^{4-7}$ Abnormalities in the human body can be detected by recording the changes in the measured voltages or potential differences in the body density. Its accuracy is low due to tissue diversity and its inability in reconstructing complex shapes.

Microwave imaging is used to recover exact electrical properties (permittivity and conductivity) in the frequency range of $300 \mathrm{MHz}$ to $30 \mathrm{GHz}$. In this technique, an array of wide band antennas is placed around the body to collect the back scattered and bi-static data. The main issues when using this technique are the high frequency of operation and small penetration depth. This technique is applicable for near fields only. It is used for breast cancer detection and treatment response monitoring. ${ }^{8}$ The portability and wearability are not possible due to the complex circuitry needed for sending and receiving wide-band signals. The accuracy is affected by the lossy characteristics of the biological tissues at microwave frequencies. Ultrasound techniques are based on the acoustic properties of the tissue and rely on the transmission, diffraction, and reflection of acoustic wave within it. Its sound frequency range is low (1-20 MHz) to ensure deep tissue penetration. ${ }^{9}$ The echoes are separated by the time delay of reception and the received signal strength. This technique is mostly suitable for soft tissues and not for bones (ie, abdominal, cardiac, urological, etc). The ultrasound device can be portable but not wearable. Its accuracy is limited. In short, EIT and ultrasound techniques give a contrast image rather than actual values of the electrical properties while the microwave imaging method has high frequency of operation hence small penetration depth within the tissue.

Microwave sensors were presented in Refs. 10-12 with an operating frequency of $915 \mathrm{MHz}$ and wearable health monitoring sensors were proposed in Refs. 13-15 and operated at $40 \mathrm{MHz}$. They had a planar geometry, high error, and large size when estimating the permittivity of a small area. Some wearable wrapped around a circular cylindrical chest model sensors were also proposed in Refs. 15,16, but the actual human chest is elliptical. Also, sub-grouping of the sensors makes the post processing of the data difficult.

Our proposed on-body monitoring system combines an RF wearable sensor with deep tissue monitoring via the changes in the electrical properties of the tissue along with its post processing algorithm. This is beneficial for patients at risk of having pulmonary edema (due to fluid accumulation in lungs) and emphysema conditions (due to air accumulation in lungs). The sensor is to be used to continuously monitor the patient condition with minimum exposure to electromagnetic (EM) radiation. The sensor will keep track of the patient condition via determining the average dielectric constant value of his/her chest. The sensor operates at $60 \mathrm{MHz}$, has small dimensions, is low cost, and of low complexity. The substrate used is a thin polyimide sheet which is flexible and can be integrated within wearable cloths (T-shirts). An inkjet printer is used for the sensor fabrication. The input power and operating frequency are low, thus reducing health risks. Moreover, the RF sensor is noninvasive and nonintrusive and its size is $4 \times 89.4 \mathrm{~cm}^{2}$ covering the complete chest The chest model used in the measurements is elliptical and close to the average adult chest size. The average error of all measured human and porcine lung cases was less than 5\% making it the most accurate using a simple algorithm. The sensor can monitor the inner tissue conditions of the human chest as deep as $11.64 \mathrm{~cm}$. The achieved dynamic range for low to high $\epsilon_{\mathrm{r}}$ variation is equal to $20 \mathrm{~dB}$ which is much higher than previous works. It can detect the presence of water in the whole area of the human upper chest.

The rest of the article is organized as follows: a brief literature survey is shown in Section 2 with a comparison table with all related works. The details of the RF sensor design are given in Section 3. Section 4 presents the dielectric constant estimation method. The measured electrical properties of different liquid phantom combinations using a dielectric assessment kit (DAK) are presented in Section 5. The experimental results for the human and porcine lung properties are gathered in Section 6. Finally, conclusions are given in Section 7.

\section{2 | LITERATURE SURVEY}

A complete literature survey was conducted and the features of various biomedical sensors are tabulated in Table 1. EIT, microwave imaging and ultrasound impedance tomography based sensors suffer from large size, high error, and portability issues. ${ }^{4-9}$ Several on body sensors operating at $915 \mathrm{MHz}$ were proposed in Refs. 10,11 while some showed textile based integration. ${ }^{12}$ These sensors had health risk due to high operating frequency, wearability issues, and can be applicable for monitoring a small area only.

Several low frequency based sensors were proposed operating around $40 \mathrm{MHz}$. Some had a planar geometry, large size, errors more than $8 \%$, and small covered areas, ${ }^{13,14}$ while others were wrapped around a circular chest model geometry with high complexity processing method (ie, grouping of estimates) and high error percentages. ${ }^{15,16}$ Some textile based sensors were also proposed in Refs. 17,18, they suffered from large size, high cost, and small area monitoring capabilities due to their planar geometry. A wearable sensor was proposed in Ref. 19 for measuring the respiratory rhythm of young children to detect respiratory disorder such as choking and asthma. The sensor was based on the variation of resistance of a knitted electrically conductive fabric, integrated into baby underwear. The resistance studies of many samples were performed and an optimum type of stitch used for knitting was selected. The drawback of such a method is the selection of the optimum type of stitch because it strongly impacts the properties of the respiratory rhythm. 
TABLE 1 Comparison of biomedical sensors available in the literature

\begin{tabular}{|c|c|c|c|c|c|c|c|c|}
\hline Reference & Category & Application & $\begin{array}{l}\text { Frequency } \\
(\mathrm{MHz})\end{array}$ & $\begin{array}{l}\text { Size } \\
(\mathrm{cm})\end{array}$ & Complexity & Error (\%) & Cost & Limits \\
\hline 3 & $\begin{array}{l}\text { Fabric sensors } \\
\text { using advance } \\
\text { signal processing } \\
\text { techniques }\end{array}$ & Cardiovascular diseases & - & Large & High & - & Very high & $\begin{array}{l}\text { Limited for monitoring } \\
\text { breathing, heart rate } \\
\text { and skin temperature, } \\
\text { advance in data } \\
\text { collection but lack in } \\
\text { deep tissue monitoring }\end{array}$ \\
\hline $4-7$ & $\begin{array}{l}\text { Electrical } \\
\text { impedance } \\
\text { tomography } \\
\text { (EIT) }\end{array}$ & $\begin{array}{l}\text { Real time imaging of } \\
\text { ventilation, detection of } \\
\text { collapsed lung }\end{array}$ & 1 to 20000 & Very large & High & High & Very high & $\begin{array}{l}\text { Limited to bed side } \\
\text { application due to } \\
\text { complex circuitry for } \\
\text { generation of variable } \\
\text { current patterns }\end{array}$ \\
\hline 8 & $\begin{array}{c}\text { Microwave } \\
\text { imaging }\end{array}$ & $\begin{array}{l}\text { Breast cancer detection and } \\
\text { treatment response } \\
\text { monitoring }\end{array}$ & $\begin{array}{l}300 \text { to } \\
30000\end{array}$ & Small & High & High & Low & $\begin{array}{l}\text { Small depth of } \\
\text { penetration, portability } \\
\text { and wearability is not } \\
\text { possible due to } \\
\text { complex circuitry }\end{array}$ \\
\hline 9 & $\begin{array}{l}\text { Ultrasound } \\
\text { impedance } \\
\text { tomography }\end{array}$ & $\begin{array}{l}\text { Abdominal, cardiac, urological, } \\
\text { fetal, pediatric and fluid } \\
\text { detection measurement and } \\
\text { analysis }\end{array}$ & $(1-20)$ & Very large & High & High & Very high & Portable but not wearable \\
\hline 10 & $\begin{array}{l}\text { Microwave } \\
\text { reflection and } \\
\text { transmission } \\
\text { measurements }\end{array}$ & $\begin{array}{l}\text { Pulmonary diagnosis and } \\
\text { monitoring }\end{array}$ & 915 & Very large & Very high & - & High & $\begin{array}{l}\text { Health risks due to high } \\
\text { frequency operation, } \\
\text { not wearable }\end{array}$ \\
\hline 11 & Microwave sensor & $\begin{array}{l}\text { Breathing, heart rate and } \\
\text { changes in lungs water } \\
\text { contents }\end{array}$ & 915 & - & Very high & - & Low & $\begin{array}{l}\text { Health risks due to high } \\
\text { frequency operation, } \\
\text { not wearable, short } \\
\text { time Fourier transform } \\
\text { based digital signal } \\
\text { processing makes it } \\
\text { more complex }\end{array}$ \\
\hline 12 & Textile EM coupler & Lung water contents monitoring & 915 & $4 \times 24$ & Low & - & High & $\begin{array}{l}\text { Monitor the permittivity } \\
\text { of a small area only }\end{array}$ \\
\hline 13 & RF sensor & Pulmonary edema monitoring & 40 & $10 \times 16$ & Low & 11 & Low & $\begin{array}{l}\text { Monitor the permittivity } \\
\text { of a small area only }\end{array}$ \\
\hline 14 & RF sensor & Lungs dielectric properties & 40 & $10 \times 16$ & Low & 8 & Low & $\begin{array}{l}\text { Monitor the permittivity } \\
\text { of a small area only }\end{array}$ \\
\hline 15 & $\begin{array}{l}\text { RF sensor with } \\
\text { pixel by pixel } \\
\text { imaging }\end{array}$ & $\begin{array}{l}\text { Cardiovascular diseases and } \\
\text { tumor growth monitoring }\end{array}$ & 40 & $5.3 \times 113$ & High & 6 & Low & $\begin{array}{l}\text { Experimental verification } \\
\text { was not done }\end{array}$ \\
\hline 16 & Flexible RF sensor & $\begin{array}{l}\text { Monitoring deep tissues } \\
\text { electrical properties }\end{array}$ & 40 & $5 \times 83$ & High & 13.5 & Low & $\begin{array}{l}\text { Subgrouping of the sensor } \\
\text { makes post processing } \\
\text { of the data difficult }\end{array}$ \\
\hline 17 & Textile sensor & Wearable applications & 40 & - & Low & - & High & $\begin{array}{c}\text { Monitor the permittivity } \\
\text { of a small area only }\end{array}$ \\
\hline 18 & Textile sensor & Wearable applications & 40 & 10 & Low & - & High & $\begin{array}{l}\text { Monitor the permittivity } \\
\text { of a small area only }\end{array}$ \\
\hline Proposed & Flexible RF sensor & $\begin{array}{l}\text { Pulmonary edema and } \\
\text { emphysema monitoring }\end{array}$ & 60 & $4 \times 89.4$ & Low & 4.83 & Low & - \\
\hline
\end{tabular}

In addition, washing or folding the sensor may produce the wrong results/misdetection. A multi-slot coaxial antenna operating at $2.45 \mathrm{GHz}$ was proposed in Ref. 20 to optimize the scattering parameters by location and size of the slots in antenna structure and limit the antenna input power to enable appropriate adjustment of the temperature of the target tissues for cancer treatment. It suffers from causing health effects due to its high frequency of operation.

Previously, we proposed an RF sensor array for estimation of multiphase oil flow in pipelines. ${ }^{21}$ In this current work, we propose an RF sensor array for lung disease detection with a totally different geometry, fabrication process, and experimental validation method with a lower operating frequency. The proposed sensor also has a higher dynamic range compared with Ref. 21 and; thus, has much higher accuracy (error $<5 \%$ ).

Compared with previous studies listed in Table 1, our proposed biomedical RF sensor has many beneficial features. It is nonintrusive, noninvasive, and smaller than others applicators. Moreover, it is inexpensive and simple to implement. The sensor is wrapped on an elliptical chest model which represents an actual scenario unlike all others that use cylinders. The sensor is robust and can be integrated within clothes/T-shirts. It can estimate different lung diseases/ 
conditions with the lowest measured error percentages compared with all mentioned works. It can monitor the inner tissues as deep as $11.64 \mathrm{~cm}$ from its surface as compared with $8 \mathrm{~cm}$ in Ref. 13. A single sensor array covers the whole area of an average adult chest, no sensor sub-grouping is required thus simpler data processing is required. The achieved dynamic range between low and high values of dielectric constant $\epsilon_{r}$ is $20 \mathrm{~dB}$ compared with $12 \mathrm{~dB}$ in Ref. 21 . The real time $\epsilon_{\mathrm{r}}$-measurements are used for the experiments using dielectric assessment kit (DAK) setup. Both homogeneous and nonhomogeneous experimental cases are discussed unlike most related works.

It should be noted that proposed RF sensor will not be able to specify the water content location but rather track the changes in its volume. It will provide continuous patient monitoring that cannot be achieved using other methods due to the harm caused by the radiation exposure.

\section{3 | RF SENSOR DESIGN}

The RF sensor consists of 38 electrodes and 37 ports. The first port is excited with $60 \mathrm{MHz} \mathrm{RF}$ signal and the remaining 37 ports were terminated with $50-\mathrm{Ohm}$ coaxial probes except the port where the measurement is taken. ${ }^{14}$ The passive receiving ports cannot act as exciters due to their small sizes. Biological issues show significant variation of $\epsilon_{\mathrm{r}}$ below $100 \mathrm{MHz}^{14}$ so the operating frequency was optimized to $60 \mathrm{MHz}$. This frequency was chosen based on the maximum achieved dynamic range for the material properties variation considered. A flexible substrate (polyimide sheet) is used with a thickness of $50 \mu \mathrm{m}$. The sensor was designed and optimized using a commercially available ANSYS HFSS software. The simulations were conducted for the frequency range $1-100 \mathrm{MHz}$ with a resonant frequency of $60 \mathrm{MHz}$. The width of first two electrodes is $4 \mathrm{~cm}$ and other electrodes have a width equal to $2 \mathrm{~cm}$. The substrate dimensions were $4.4 \times 89.4 \times 0.005 \mathrm{~cm}^{3}$. The sensor design is based on the idea introduced in our previous work ${ }^{21}$ and other works ${ }^{13,14}$ with a totally different geometry. Several designs were investigated, and the proposed design gave the best dynamic range response and smallest size. The first two electrodes were designed to operate at $60 \mathrm{MHz}$ under the best possible matching conditions to perform as the signal exciter. The remaining 36 electrodes receive the radiated fringing fields. The gap between the electrodes was optimized to $0.22 \mathrm{~cm}$. The proposed design with detailed dimensions is shown in Figure 1A,B.

The sensor was wrapped around an elliptical average adult human chest upper torso model with two ellipse axis given as $33.2 \mathrm{~cm}$ and $23.28 \mathrm{~cm}$. The upper torso of the human body has a length of $18.29 \mathrm{~cm} .^{22}$ The perimeter of an

$89.4 \mathrm{~cm}$

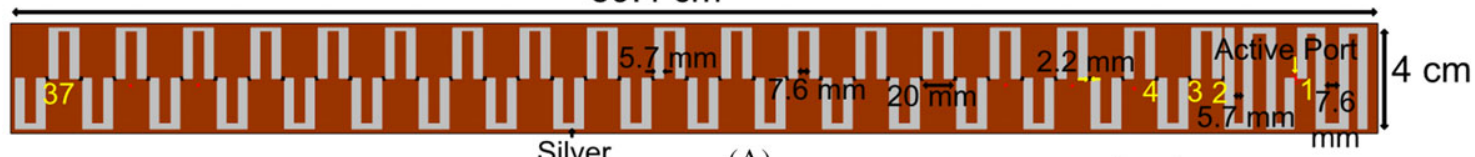

Silver

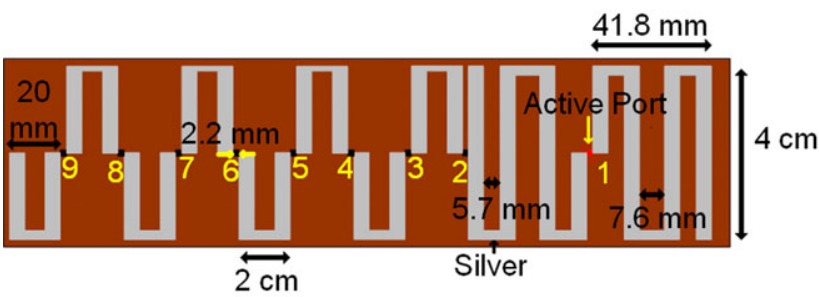

(B)

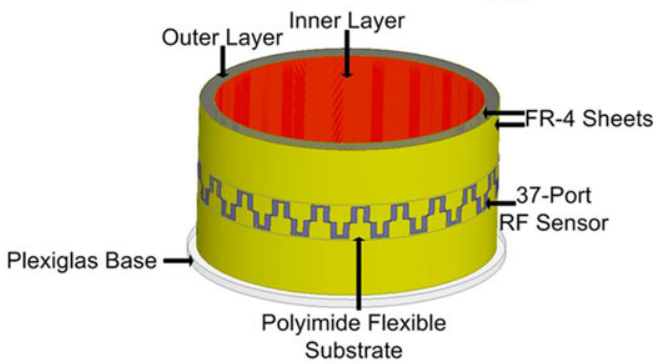

(C)

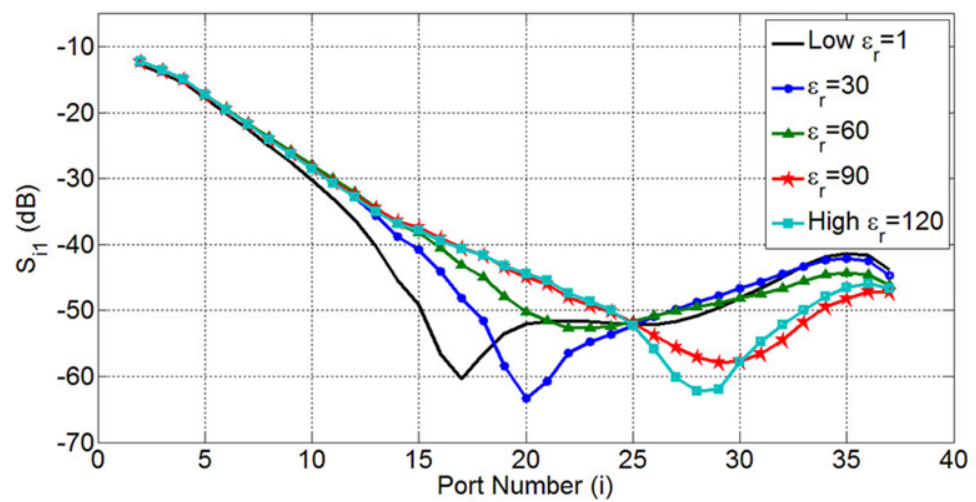

(D)

FIGURE 1 Proposed designed planar RF sensor: (A) complete view, (B) enlarged view for first 10 electrodes, (C) sensor wrapped around an averaged adult chest model, and (D) comparison between scattering parameters $S_{\mathrm{i} 1}$ for different values of electric permittivity $\epsilon_{\mathrm{r}}$ 
TABLE 2 Electrical properties of different materials used for designing of RF sensor

\begin{tabular}{|c|c|c|c|c|c|}
\hline Material & Thickness (cm) & Relative permittivity & Loss tangent & Electric conductivity (S/m) & Reference \\
\hline Polyimide sheet & 0.005 & 3.4 & 0.01 & - & 24 \\
\hline FR-4 sheet & 0.07874 & 4.8 & 0.017 & - & 25 \\
\hline Plexiglas base & 1 & 2.5 & 0.08 & - & 26 \\
\hline Outer layer & 1.5 & 40.6 & 2.33 & 0.38 & 14,15 \\
\hline Inner layer & 31.62 & $1-120$ & $2-3$ & $0.3-0.5$ & 14 \\
\hline
\end{tabular}

average human chest is $89.4 \mathrm{~cm}$ (which is also the substrate width of the RF sensor) having an elliptical shape with major radius $16.6 \mathrm{~cm}$ and minor radius $11.64 \mathrm{~cm}^{23}$ The average thickness of the outer chest layer (skin, fat, muscles, and bones) is $1.5 \mathrm{~cm} .{ }^{14}$ The wrap around design of the proposed $\mathrm{RF}$ sensor is shown in Figure 1C. The electrical properties of the substrate, FR-4 sheet, plexiglas base, outer layer, and inner layer of the chest model are summarized in Table 2. If outer layer properties change, the model needs to be resimulated to extract new curves and update the $\epsilon_{\mathrm{r}}$-estimation equation. The dielectric constant of the inner layer was varied from 1 to 120 . The scattering coefficients $\left(S_{\mathrm{i} 1}\right)$ were obtained for different values of electrical permittivity $\left(\epsilon_{\mathrm{r}}\right)$, namely $1,30,60,90$, and 120 inside the chest, where $i$ is the port number. The comparison between $S_{\mathrm{i} 1}$ curves of different $\epsilon_{\mathrm{r}}$ values is shown in Figure 1D. The maximum achieved dynamic range between low and high $\epsilon_{\mathrm{r}}$ values was $20 \mathrm{~dB}$ (which is the difference of largest and smallest scattering coefficient values at port 17) at port 17, while the achieved dynamic range in Refs. 14,16, using $\epsilon_{\mathrm{r}}$ values from 1 to 180 was $22 \mathrm{~dB}$ for planar or semi planar sensors. The dynamic range is the range (in $\mathrm{dB}$ ) associated with the most affected port by the inner layers (port 17 in our case) from the active one for the two extreme $\epsilon_{\mathrm{r}}$ values expected, that is, 1 and 120, in current investigation. The dynamic range of $S_{\mathrm{i} 1}$ should be large enough to accurately map the dielectric properties. With large dynamic range, we can detect small changes in $\epsilon_{\mathrm{r}}$ more precisely which is an essential aspect of monitoring illness or recovery. There is no need for RF sensor sub-grouping as done in Ref. 16 which makes the post processing of the data difficult. By changing the $\epsilon_{\mathrm{r}}$ values, a shift in $S_{\mathrm{i} 1}$ curves was observed which will improve its accuracy for $\epsilon_{\mathrm{r}}$ estimation using the Least Squares (LS) method.

\section{1 | Specific absorption rate}

Specific absorption rate (SAR) is a metric that evaluates the safety limits for different devices producing EM radiation inside the human tissue. SAR should be evaluated for wireless medical devices and all kinds of cell phones. The power absorbed by the tissue surrounding the antenna/sensor should not exceed the standard limits. According to IEEE, the $10 \mathrm{~g}$ averaged SAR value should not exceed $2 \mathrm{~W} / \mathrm{kg}$. The Federal Communication Commission (FCC) limits $1 \mathrm{~g}$ average SAR value to $1.6 \mathrm{~W} / \mathrm{kg}$. According to IEEE and FCC recommendations, the whole body SAR value is limited to $0.08 \mathrm{~W} / \mathrm{Kg}^{27-29}$. The SAR-parameter of the designed RF sensor was calculated using ANSYS HFSS internal engine. SAR is defined as follows: ${ }^{30}$

$$
\mathrm{SAR}=\int_{\text {Sample }} \frac{\sigma(r)|E(r)|^{2}}{\rho(r)} d r
$$

where, $|E(r)|^{2}$ is square of the electric field strength, $\sigma$ is the tissue sample $r$ electrical conductivity, and $\rho$ is the mass density of the tissue sample. We calculated the local SAR. The ANSYS HFSS software uses Equation (1) to calculate the SAR at each mesh point on an overlay plot. It then interpolates the values between the mesh points across the plot. The SAR values were calculated in watts per $\mathrm{kg}$. The SAR was evaluated with an applied transmitting power of $1 \mathrm{~W}$. The mass of tissue was kept $1 \mathrm{~g}$ and material density $1 \mathrm{~g} / \mathrm{cm}^{3}$. ${ }^{31}$ The SAR values are greatly affected by the applied transmitting power level. ${ }^{31}$ In this work we considered that the outer layer electrical properties remained the same. The SAR was calculated by changing the inner layer electrical properties only with maximum conductivity value of $0.5 \mathrm{~S} / \mathrm{m}$ to analyze the worst case scenario of SAR. The maximum value of SAR was always near the first port (exciting source) for all analyzed cases, namely for $\epsilon_{r}=(1,30,60,90,108,120)$ and the obtained values were far away from the FCC and IEEE standards as shown in Table 3.

We used a $1 \mathrm{~cm}$ thick plexiglas sheet to form the base of the modeled human chest torso. The base is used to hold the inner layer and outer layer separation FR-4 sheets of $0.8 \mathrm{~mm}$ thickness. These FR-4 sheets were added in the simulation model and their effect was considered. The base was not considered in SAR calculations (note that the radiation is inside the ellipse and not toward the base). By adding the plexiglas base to the simulation mode, the SAR values are not expected to be affected as the sensor radiation is not toward it and its far away from the sensor center (vertical distance from center of the sensor to base is $9.15 \mathrm{~cm}$ ).

TABLE 3 SAR values calculated using ANSYS HFSS software

$\begin{array}{llllll}\text { Inner layer } & \boldsymbol{\epsilon}_{\mathbf{r}}=\mathbf{1} & \boldsymbol{\epsilon}_{\mathbf{r}}=\mathbf{3 0} & \boldsymbol{\epsilon}_{\mathbf{r}}=\mathbf{6 0} & \boldsymbol{\epsilon}_{\mathbf{r}}=\mathbf{9 0} & \boldsymbol{\epsilon}_{\mathbf{r}}=\mathbf{1 0 8} \\ \mathrm{SAR}(\mathrm{W} / \mathrm{kg}) & 0.035692 & 0.0097286 & 0.0088508 & 0.0071432 & 0.0077559\end{array}$


(A)

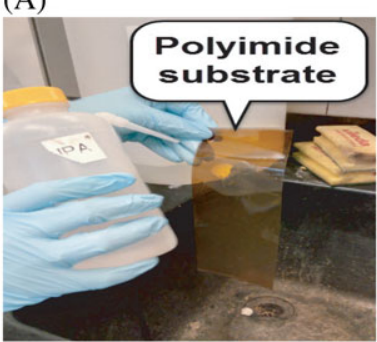

(C)

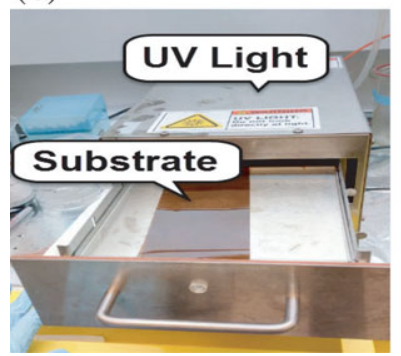

(B)

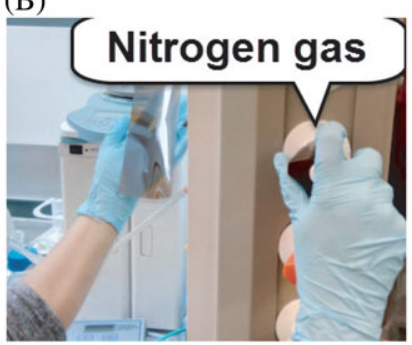

(D)

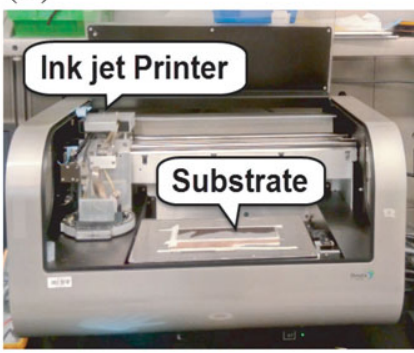

FIGURE 2 RF sensor printing steps: (A) substrate washing with isopropyl alcohol (IPA), (B) drying with nitrogen gas, (C) UV light curing, and (D) substrate fixing on inkjet printer

\section{2 | Sensor fabrication using silver inkjet printing}

The proposed RF sensor was fabricated using a silver inkjet printer at the IMPACT lab, King Abdullah University of Science and Technology (KAUST), Saudi Arabia. The sensor was printed using advanced nano products (ANP) silver ink. Since the available inkjet printer can print only A4 size sheets, the proposed sensor was divided into five parts. The first step was washing the substrate with isopropyl alcohol (IPA). The second step was the drying process of the polyimide substrate that was performed using nitrogen gas. In the third step, ultra-violet (UV) light curing for $1 \mathrm{~min}$ time period was performed for good silver layer printing on the polyimide. Increasing the UV light curing time will increase the silver ink spreading on the substrate. The forth step was fixing of the substrate on inkjet printer. All these steps are shown in Figure 2. Three ANP silver ink layers were printed to achieve good conductivity values. After each layer

printing, 10 min heating is applied at $130^{\circ} \mathrm{C}$ and after the last layer printing, heating time is increased to $15 \mathrm{~min}$. The drop spacing of the ANP ink during printing was optimized to $30 \mu \mathrm{m}$. Decreasing the drop spacing results in ink spreading on the substrate.

The five fabricated parts of the sensor were joined using double sided tape. The final fabricated RF sensor prototype without coaxial probes is shown in Figure 3A, the flexibility of the RF sensor is in Figure 3B on a shirt flexible material, the scaled RF sensor with $30 \mathrm{~cm}$ scale is presented in Figure 3A,D shows the fabricated RF sensor with 50-Ohms coaxial probes attached to each port. The constructed model is used as a proof of concept model. In a commercial one, the probes can be replaced with smaller ICs that are capable of power measurements and may wirelessly transfer their values to a nearby processing unit.

\section{3 | Human chest upper torso design}

The human upper chest torso model was designed in the Fablab at King Fahd University of Petroleum and Minerals (KFUPM), Saudi Arabia, using a computer numerical control (CNC) machine. A plexiglas sheet of $1 \mathrm{~cm}$ thickness was used for the human chest torso base. Two elliptical grooves for the outer and inner layers were modeled with $0.5 \mathrm{~cm}$ thickness to fix the flexible $0.8 \mathrm{~mm}$ FR- 4 sheets that were used to separate the inner and outer layer solutions from one another. The sheets separating inner and outer layers were made of FR-4 material and they were modeled in ANSYS HFSS software during the simulations to take their effect into the dynamic range and LS method calculations and to reflect the measurement setup. The height of the human upper chest torso was $18.29 \mathrm{~cm}$. Super glue was used to join the FR-4 sheets and epoxy glue was used to fix the FR-4 sheets in the grooves. Figure 4A shows the plexiglas base design on the $\mathrm{CNC}$ machine with software commands running on the computer. Figure 4B-D shows the top, front, and side views of the designed human upper chest elliptic torso, respectively.
(A)

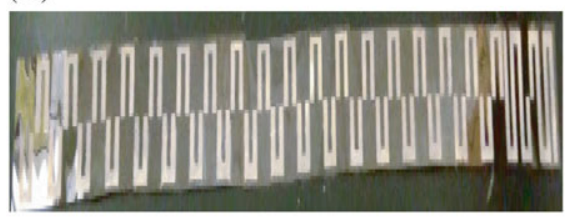

(C)

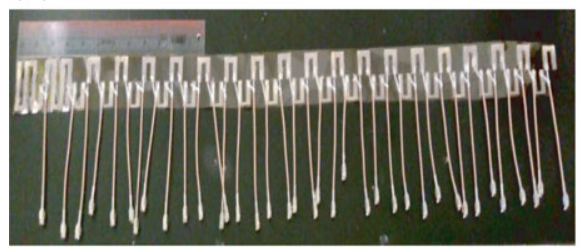

(B)

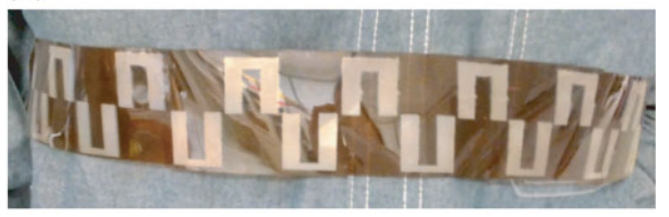

(D)

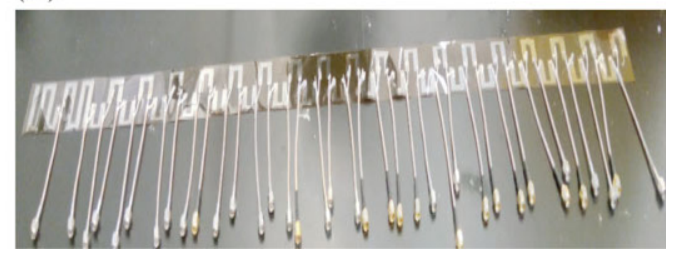

FIGURE 3 Fabricated RF sensor: (A) RF sensor without coaxial probes, (B) flexible RF sensor on a shirt, (C) scaled RF sensor compared with $30 \mathrm{~cm}$ ruler, and (D) RF sensor with coaxial probes 
(A)

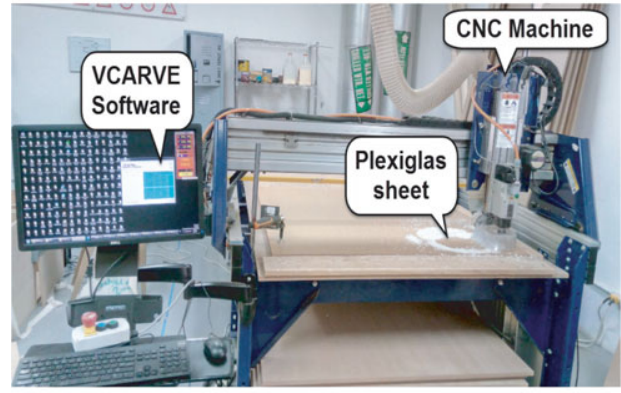

(C)

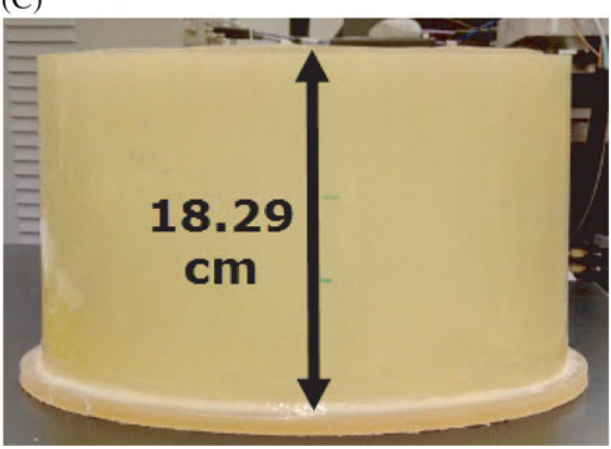

(B)

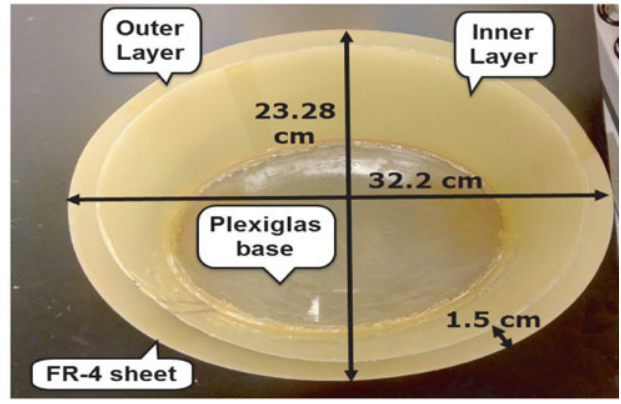

(D)

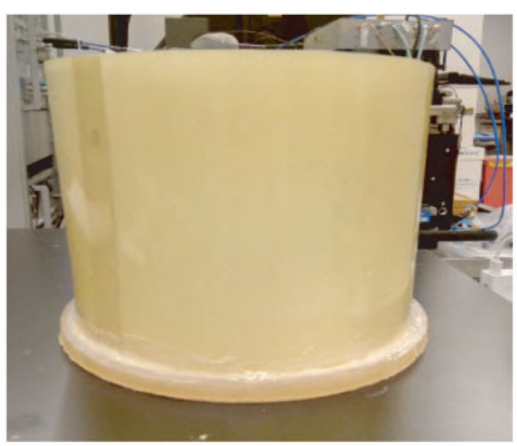

FIGURE 4 Human chest upper torso phantom design: (A) plexiglas base design, (B) top view, (C) front view, and (D) side view

\section{I AVERAGE DIELECTRIC CONSTANT ESTIMATION}

The dielectric constant can be estimated using a similar expression as below ${ }^{14}$ Equation (2),

$$
\epsilon_{\mathrm{r}}=\sum_{i=2}^{37} w_{\mathrm{i}-1} S_{\mathrm{i} 1}
$$

Following Equation $(2)^{13,14} w_{\mathrm{i}-1}$ are the weight coefficients, $S_{\mathrm{i} 1}$ are the scattering coefficients, and $i$ is the port number. $S_{\mathrm{i} 1}$ distributions were determined using ANSYS HFSS software by varying the $\epsilon_{\mathrm{r}}$ inside the inner layer of the chest model from 1 to 120 , its conductivity from 0.3 to $0.5 \mathrm{~S} / \mathrm{m}$ and loss tangent from 2 to 3 . The resultant overdetermined matrix consisting of 480 rows and 36 columns was solved using the LS method to obtain the weight coefficients as demonstrated in Refs. 14,32. To get the $\epsilon_{\mathrm{r}}$-estimates for both simulated and average measured $S_{\mathrm{i} 1}$ values, the following formula was used based on the simulation model solution:

$$
\begin{aligned}
\epsilon_{\mathrm{r}}= & 26.66 S_{2,1}-8.96 S_{3,1}+3.55 S_{4,1}+13.87 S_{5,1} \\
& -7.52 S_{6,1}-4.88 S_{7,1}+0.79 S_{8,1}-4.68 S_{9,1}+4.74 S_{10,1} \\
& -9.83 S_{11,1}+15.11 S_{12,1}-13.11 S_{13,1}+11.8 S_{14,1} \\
& +3.01 S_{15,1}+12 S_{16,1}-17.62 S_{17,1}+7.45 S_{18,1} \\
& -25.04 S_{19,1}+20.31 S_{20,1}+7.53 S_{21,1}-26.62 S_{22,1} \\
& +13.77 S_{23,1}+5.92 S_{24,1}+0.15 S_{25,1}-2.09 S_{26,1} \\
& -0.02 S_{27,1}-3.64 S_{28,1}-10.36 S_{29,1}+14.64 S_{30,1} \\
& -3.78 S_{31,1}+0.01 S_{32,1}-1.32 S_{33,1}+3.76 S_{34,1} \\
& -5.96 S_{35,1}+3.32 S_{36,1}-6.29 S_{37,1}
\end{aligned}
$$

\section{5 | ELECTRICAL PROPERTIES MEASUREMENT USING A DIELECTRIC ASSESSMENT KIT}

A Dielectric Assessment Kit (DAK) setup is used to measure the electrical properties (permittivity, loss tangent, and conductivity) of any liquid solution within the created phantom. Figure 5A shows the DAK measurement setup. Glycerin is important for breast imaging. Its permittivity can be varied considerably because it is soluble in water. It is nontoxic and ideal from a human safety prospective. ${ }^{33}$ The human chest model with fixed outer and different inner layer electrical properties are formed using a mixture of sodium chloride $(\mathrm{NaCl})$, water, isopropyl alcohol (IPA), and glycerin. The permittivity of the available solutions is measured using the DAK. Figure 5B shows the measured dielectric constant for glycerin, water, and IPA in the frequency range between 10 and $100 \mathrm{MHz}$. Due to its low dielectric constant, IPA can be used in the inner layer during the experiments for emphysema cases. Different solutions were optimized for normal, edema and emphysema infected human lungs. A $10 \mathrm{~mL}$ IPA with $80 \mathrm{~mL}$ glycerin solution is used for a normal human lung. For the edema infected lung, a mixture of $200 \mathrm{~mL}$ glycerin, $40 \mathrm{~mL}$ water, and $10 \mathrm{~g} \mathrm{NaCl}$ is used. Porcine lung properties are formed using a $200 \mathrm{~mL}$ water with $0.7 \mathrm{~g} \mathrm{NaCl}$ solution. The $\mathrm{NaCl}-$ water solution was used to increase the permittivity, electric conductivity, and loss tangent values. The human chest outer layer properties are optimized using $70 \mathrm{~mL}$ IPA, $50 \mathrm{~mL}$ glycerin, $20 \mathrm{~mL}$ water, and $5 \mathrm{~g} \mathrm{NaCl}$ solution. The obtained dielectric constant values in the 


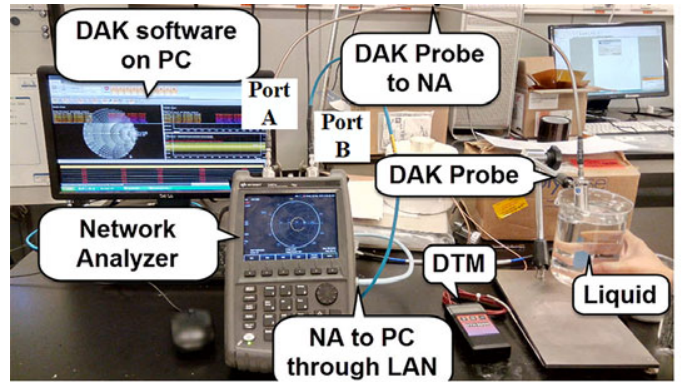

(A)

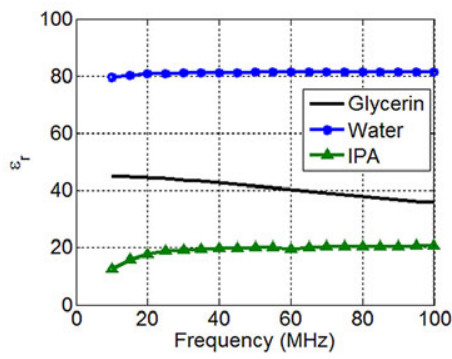

(B)

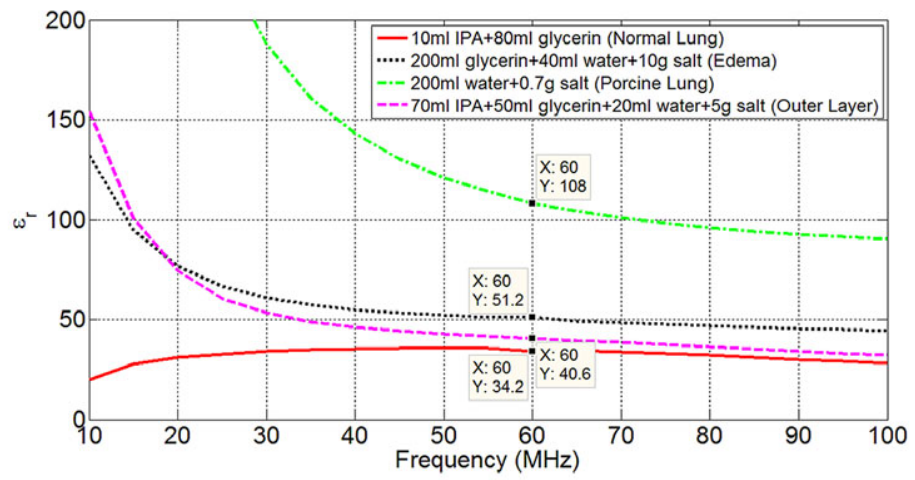

(C)

FIGURE 5 Measurement setup of DAK, namely: DAK (A) frequency-dependent characteristics of electric permittivity for: (B) glycerin, water and isopropyl alcohol (emphysema), (C) normal lung, edema, porcine lung, and outer chest layer

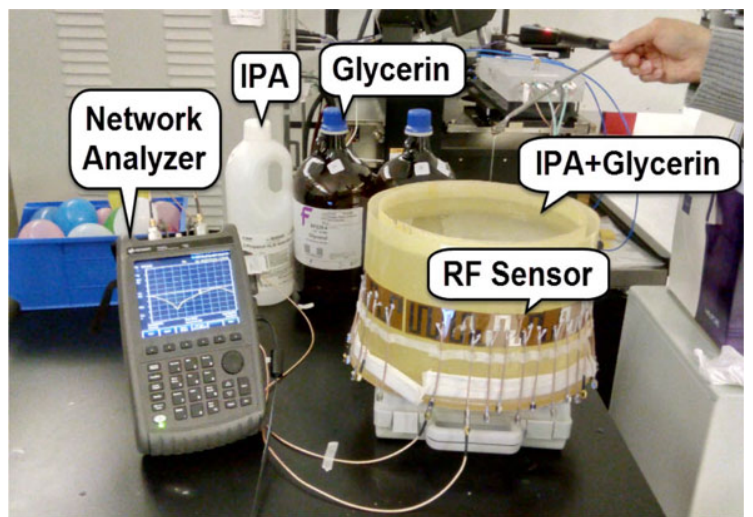

(A)

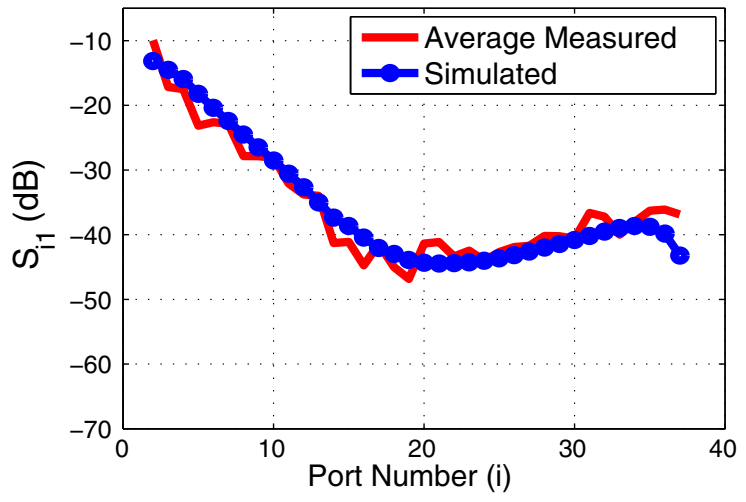

(C)

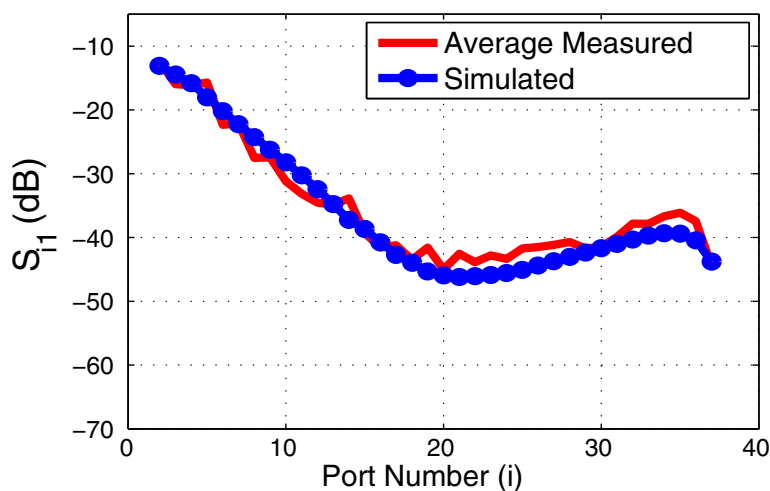

(B)

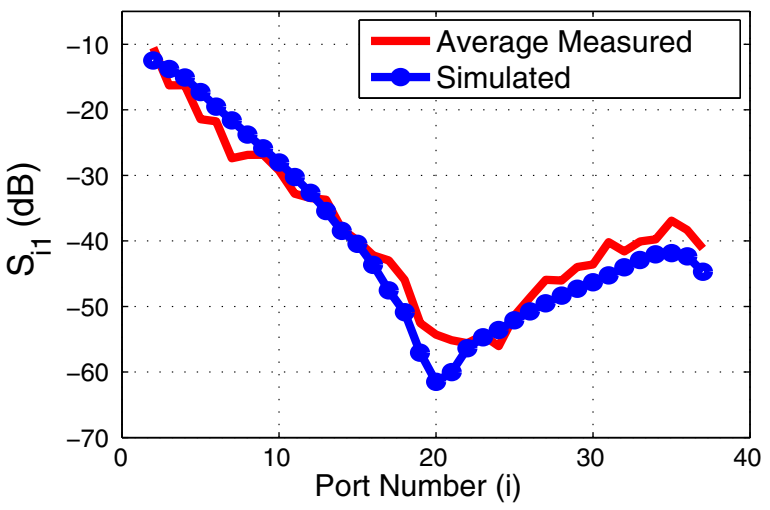

(D)

FIGURE 6 Measurement setup in the case of normal lung tissue (A). (A) Measurement setup, comparison of average measured and simulated $S_{\text {i1 }}$ for: (B) normal lung, (C) emphysema, and (D) edema models 
TABLE 4 Comparison of exact, simulated, and average measured $\epsilon_{r}$-values for normal human lung and different diseased lung tissue

\begin{tabular}{|llllc} 
Category & Exact $\boldsymbol{\epsilon}_{\mathbf{r}}$ & Simulated $\boldsymbol{\epsilon}_{\mathbf{r}}$ & Measured $\boldsymbol{\epsilon}_{\mathbf{r}}$ & Simulated error $(\%)$ \\
\hline Normal lung & 34.2 & 33.74 & 32.99 & 3.54 \\
\hline Emphysema & 19.5 & 19.47 & 18.72 & 4.35 \\
\hline Edema & 51.2 & 51.74 & 53.67 & 0.17 \\
\hline
\end{tabular}

frequency range of 10-100 $\mathrm{MHz}$ for all mentioned cases are shown in Figure 5C.

\section{6 | EXPERIMENTAL RESULTS}

The values of electric permittivity $\left(\epsilon_{\mathrm{r}}\right)$ for the normal lung, emphysema, and edema conditions are 34.2, 16.9, and 51.2, respectively, as stated in Ref. 13. The outer layer electrical properties are formed using a mixture of isopropyl alcohol, $\mathrm{NaCl}$, water, and glycerin. A mixture of $1190 \mathrm{~mL}$ IPA, $850 \mathrm{~mL}$ glycerin, $340 \mathrm{~mL}$ water, and $85 \mathrm{~g} \mathrm{NaCl}$ filled the outer layer of the upper chest torso. The achieved $\epsilon_{\mathrm{r}}$ was 40.6 the same as stated in Ref. 15. An $8000 \mathrm{~mL}$ glycerin and $1000 \mathrm{~mL}$ isopropyl alcohol mixture filled the inner layer of the torso with $\epsilon_{\mathrm{r}}=34.2$ which is similar to a normal lung tissue. Figure 6A shows the measurement setup for normal lung testing. Port A of the vector network analyzer (VNA) is

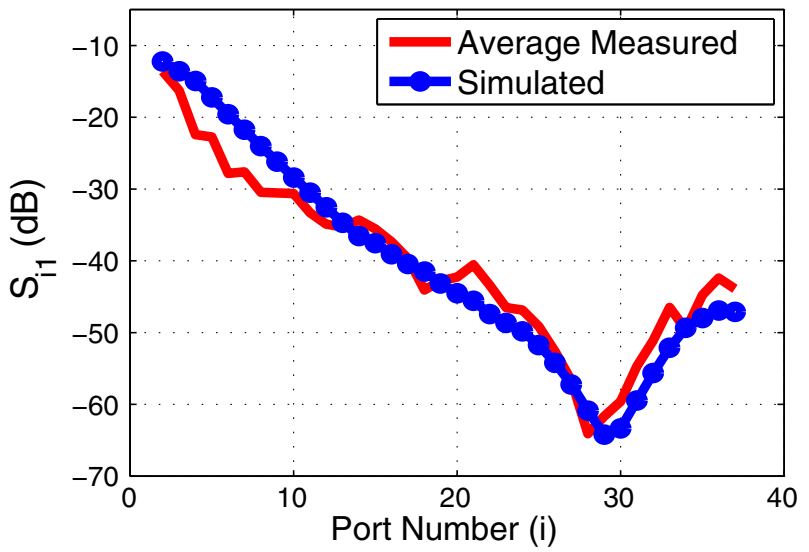

(A)

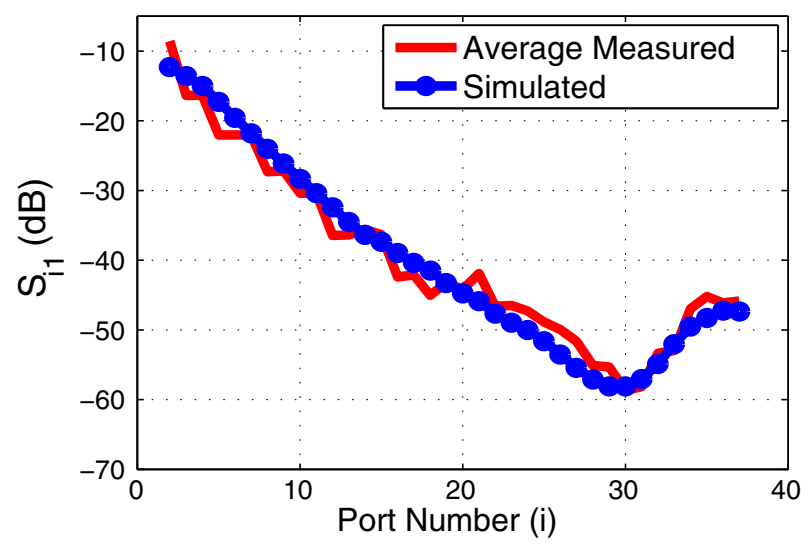

(C) connected to the active port and port B is switched to other ports (2-37 ports) for $S_{\mathrm{i} 1}$ measurements. Each port measurement was taken three times and the comparison of the average measured and simulated $S_{\mathrm{i} 1}$-curves in the case of normal lung tissue are shown in Figure 6B. It is worth noting that averaged measured $S_{\mathrm{i} 1}$ are in good agreement with the simulated ones.

IPA filled the inner layer of the torso with $\epsilon_{\mathrm{r}}=19.5$ for the emphysema sample. Figure $6 \mathrm{C}$ shows the comparison of average measured and simulated $S_{\mathrm{i} 1}$-distributions for the emphysema test model. A mixture of $7500 \mathrm{~mL}$ glycerin, $1500 \mathrm{~mL}$ water, and $375 \mathrm{~g} \mathrm{NaCl}$ solution filled the inner layer of the chest upper torso with $\epsilon_{\mathrm{r}}=51.2$ which is similar to the edema case. Figure $6 \mathrm{D}$ shows the comparison of average measured and simulated $S_{\mathrm{i} 1}$-curves for edema testing. It is important to note that the averaged measured $S_{\mathrm{i} 1}$ values are matching their simulated ones. Table 4 shows the exact, simulated, and measured $\epsilon_{\mathrm{r}}$-values using Equation (3) with

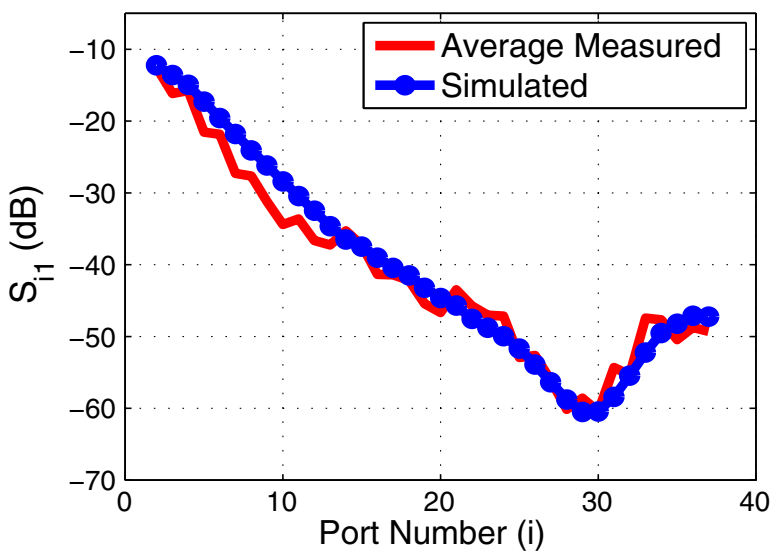

(B)

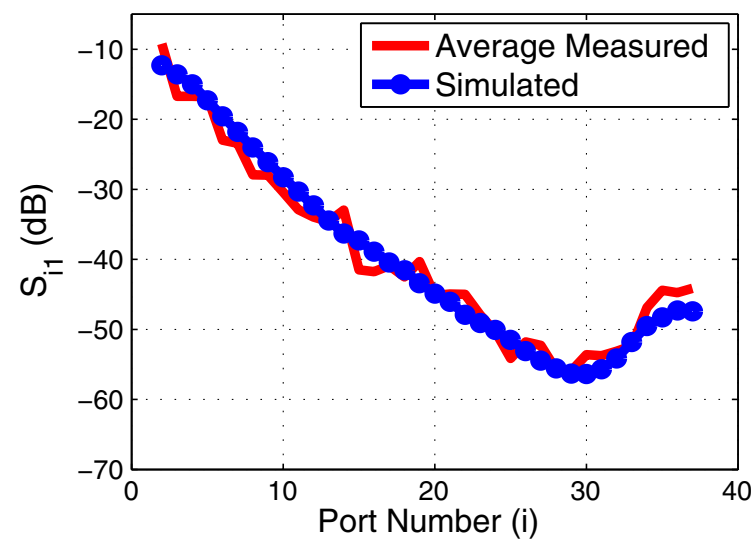

(D)

FIGURE 7 Comparison of average measured and simulated $S_{\mathrm{i} 1}$ for: (A) water and salt mixture (porcine lung), (B) adding 6 water balls, (C) adding 12 water balls, and (D) adding 18 water balls 
TABLE 5 Comparison of exact, simulated, and average measured $\epsilon_{\mathrm{r}}$-values for porcine lung with different pulmonary edema stages

\begin{tabular}{|c|c|c|c|c|c|}
\hline Category & Exact $\epsilon_{\mathbf{r}}$ & Simulated $\epsilon_{\mathbf{r}}$ & Measured $\epsilon_{\mathbf{r}}$ & Simulated error $(\%)$ & Measured error (\%) \\
\hline Water + salt $(\mathrm{NaCl})$ & 108 & 109.31 & 110.89 & 1.21 & 2.68 \\
\hline Water + salt $(\mathrm{NaCl})$ with 6 water balls & 104 & 104.83 & 104.9 & 0.79 & 0.87 \\
\hline Water + salt $(\mathrm{NaCl})$ with 12 water balls & 100 & 100.3 & 102.18 & 0.3 & 2.18 \\
\hline Water + salt $(\mathrm{NaCl})$ with 18 water balls & 96 & 96.52 & 98.69 & 0.55 & 2.8 \\
\hline
\end{tabular}

an average measured estimation error less than $4.83 \%$. The simulated error is due to LS method weight estimation error.

Another test was conducted for a porcine lung to show the applicability of the sensor under different conditions. The dielectric constant for the porcine lung is equal to $106.8 .^{13}$ The normal water and $\mathrm{NaCl}$ solution filled the inner layer of the chest upper torso in ratio: $0.7 \mathrm{~g}$ of $\mathrm{NaCl}$ in $200 \mathrm{~mL}$ of water. The $9000 \mathrm{~mL}$ water with $3.15 \mathrm{~g}$ of $\mathrm{NaCl}$ is used for this case. The obtained $\epsilon_{\mathrm{r}}$-value was 108 which is similar to the porcine lung tissue. Figure 7A shows the comparison of average measured and simulated $S_{\mathrm{i} 1}$. The average measurement of dielectric constant is close to performed simulation.

To consider different stages of pulmonary edema and making the chest inner layer more nonhomogeneous, small balloons of $200 \mathrm{~mL}$ size were filled with water and inserted to this layer. The effective dielectric constant $\left(\epsilon_{\mathrm{r}}\right)$ of water and $\mathrm{NaCl}$ mixture including the water balloons is calculated using $^{34}$ Equation (4),

$$
\sqrt{\epsilon_{r}}=d \sqrt{\epsilon_{\text {water }+ \text { salt }}}+w \sqrt{\epsilon_{\text {water }}}
$$

where, $d$ is the volume fraction of water and $\mathrm{NaCl}$ solution, $w$ is the volume of water, $\epsilon_{\mathrm{water}}+$ salt is the dielectric constant of water and $\mathrm{NaCl}$ mixture with a value of 108 , and $\epsilon_{\text {water }}$ is the dielectric constant of water with a value of 81 . Adding 6 water balls to the inner phantom layer, the obtained average permittivity using Equation (4) was equal to 104. Figure 7B compares the average measured and simulated $S_{\mathrm{i} 1}$-distributions. The average measurement of the dielectric constant is in good agreement with the simulated one.

When adding 12 water balls in the inner layer, the calculated effective permittivity using Equation (4) was 100. Figure 7C shows the comparison of average measured and simulated $S_{\mathrm{i} 1}$-distributions. Similarly, adding 18 water balls the comparison of the measured and simulated $S_{\mathrm{i} 1}$-curves is shown in Figure 7D. The average measurements are matching well with the simulated ones in all analyzed cases. Table 5 shows the exact, simulated and measured $\epsilon_{\mathrm{r}}$-values using Equation (3), for all the cases of a porcine lung tissue with an average measured error of less than $2.8 \%$.

\section{7 | CONCLUSIONS}

A 37-port inkjet printed RF based low complexity, low cost, and noninvasive human chest sensor for average permittivity estimation of different lung diseases is presented that can be integrated with cloths easily. The sensor was built on a flexible polyimide substrate of thickness $50 \mu \mathrm{m}$. It was found that the sensor can estimate the dielectric constant for a human lung (normal, edema infected, and emphysema infected) with maximum average error of $4.83 \%$. To differentiate between different stages of pulmonary edema, the inner layer of an elliptical upper torso model was filled with water and salt $(\mathrm{NaCl})$ mixture (porcine lung case) and water balls were added to the inner layer with the increment of six water balls. The average error for pulmonary edema stages detection was found to be less than $2.8 \%$.

\section{ACKNOWLEDGMENTS}

This project was partially funded by the National Plan for Science, Technology and Innovation (Maarifah)—King Abdulaziz City for Science and Technology-through the Science and Technology Unit at King Fahd University of Petroleum and Minerals (KFUPM) - the Kingdom of Saudi Arabia, under grant number 15-MED-3742-04. Also, this project was supported by KFUPM-KAUST Project number KAUST-002. The authors would like to thank King Abdullah University of Science and Technology (KAUST) for their support in fabrication and experimental validation of the proposed sensor.

\section{ORCID}

Muhammad Tayyab (D) http://orcid.org/0000-0003-1860-7372

Mohammad S. Sharawi (D) http://orcid.org/0000-0003-4450-8212

\section{REFERENCES}

1. Reig C, Navarro EA. Printed antennas for sensor applications: a review. IEEE Sens J. 2014;14(8):2406-2418

2. Bonfiglio A, Rossi DD. Wearable Monitoring Systems. New York, NY: Springer; 2011.

3. Paradiso R, Loriga G, Taccini N. A wearable health care system based on knitted integrated sensors. IEEE Trans Technol Biomed. 2005;9(3):337-345.

4. Salman S. A Wearable Real-Time and Non-Invasive Thoracic Cavity Monitoring System [PhD thesis]. The Ohio State University; 2015.

5. Adlert A, Berthtaume Y, Guardo R, et al. Imaging of pulmonary edema with electrical impedance tomography. In: 17th International Conference of the Engineering in Medicine and Biology Society, 1995;1:557-558.

6. Shahidi AV, Guardo R, Savard P. On the monitoring of pulmonary edema by impedance tomography. In: 16th Annual International Conference of the IEEE Engineering in Medicine and Biology Society, 1994;1:532-533.

7. Rezaeieh SA, Abbosh AM. Review of systems for the detection and monitoring of accumulated fluids in the human torso. In: International Symposium on Antennas and Propagation (ISAP), 2015.

8. Meaney PM, Kaufman PA, Muffly LS, et al. Microwave imaging for neoadjuvant chemotherapy monitoring: initial clinical experience. Breast Cancer Res. 2013;15(2):1-16.

9. Narouze SN. Atlas of Ultrasound-Guided Procedures in Interventional Pain Management. New York, NY: Springer; 2018.

10. Pedersen PC, Johnson CC, Durney $\mathrm{CH}$, Bragg DG. Microwave reflection and transmission measurements for pulmonary diagnosis and monitoring. IEEE Trans Biomed Eng. 1978;25(1):40-48. 
11. Celik N, Gagarin R, Youn $H$, et al. A noninvasive microwave sensor and signal processing technique for continuous monitoring of vital signs. IEEE Antenna Wirel Propag Lett. 2011;10:286-289.

12. Perron RRG, Huang GC, Iskander MF. Textile electromagnetic coupler for monitoring vital signs and changes in lung water content. IEEE Antenna Wirel Propag Lett. 2015;14:151-154.

13. Salman S, Wang Z, Colebeck E, Kiourti A, Topsakal E, Volakis JL. Pulmonary edema monitoring sensor with integrated body-area network for remote medical sensing. IEEE Trans Antenna Propag. 2014;62(5):2787-2794.

14. Salman S, Psychoudakis D, Volakis JL. Determining the relative permittivity of deep embedded biological tissues. IEEE Antenna Wirel Propag Lett. 2012;11:1694-1697.

15. Islam MA, Kiourti A, Volakis JL. A novel method of deep tissue biomedical imaging using a wearable sensor. IEEE Sens J. 2016;16(1):265-270.

16. Salman S, Lee LZ, Volakis JL. A wearable wrap-around sensor for monitoring deep tissue electric properties. IEEE Sens J. 2014;14(8):2447-2451.

17. Salman S, Wang Z, Kiourti A, et al. A non-invasive lung monitoring sensor with integrated body-area network. In: IEEE International Microwave Workshop Series on RF and Wireless Technologies for Biomedical and Healthcare Applications (IMWS-BIO), 2013;1:1-3.

18. Zhang L, Wang Z, Volakis JL. Textile antennas and sensors for body-worn applications. IEEE Antenna Wirel Propag Lett. 2012;11:1690-1693.

19. Jakubas A, Tondyra E. A study on application of the ribbing stitch as sensor of respiratory rhythm in smart clothing designed for infants. J Text Inst. 2018;1:1-9.

20. Gas P. Optimization of multi-slot coaxial antennas for microwave thermotherapy based on the S11-parameter analysis. Biocybern Biomed Eng J. 2017;37:78-93.

21. Tayyab M, Sharawi MS, Al-Sarkhi A. A radio frequency sensor Array for dielectric constant estimation of multiphase oil flow in pipelines. IEEE Sens J. 2017;17(18):5900-5907.

22. Hanavan EP. A Mathematical Model of the Human Body. Ohio: Behavioral Science Laboratory, Air Force Base; 1964.

23. https://msis.jsc.nasa.gov/sections/section03.htm. 2018.

24. http://www.goodfellow.com/A/Polyimide-Film.html. 2018.

25. http://www.americanepoxy.com. 2018.

26. https://www.plexiglas.com/export/sites/plexiglas/.content/medias/ downloads/sheet-docs/plexiglas-general-information-and-physicalproperties.pdf. 2018.

27. IEEE Standard for Safety Levels With Respect to Human Exposure to Radio Frequency Electromagnetic Fields, $3 \mathrm{kHz}$ to $300 \mathrm{GHz}$ IEEE. IEEE Standard C95.1-2005. 2005.

28. FCC guidelines for evaluating the environmental effects of radio frequency radiation. FCC, Washington DC. 1996.

29. Miaskowski A, Gas P, Krawczyk A. SAR calculations for titanium barimplant subjected to microwave radiation. In: 17th International Conference Computational Problems of Electrical Engineering (CPEE). 2016;1:1-4.

30. http://www.ozeninc.com/wp-content/uploads/2015/05/OEI_Biomedical_ WhitePaper_Final.pdf. 2018.

31. Shrivastava $P$, Rama Rao T. Specific absorption rate distributions of a tapered slot antenna at $60 \mathrm{GHz}$ in personal wireless devices. IEEE Antennas Propag Mag. 2017;59(6):140-146.

32. Strang G. Linear Algebra and its Application. Belmont, CA: Brooks Cole; 2006.

33. Meaney PM, Fox CJ, Geimer SD, et al. Electrical characterization of glycerin: water mixtures: implications for use as a coupling medium in microwave tomography. IEEE Trans Microw Theory Tech. 2017;25(5):1471-1478.

34. Xie N, Zhang H, Gao S, et al. Research of measuring instrument for water-in-oil percentage with capacitance sensor. In: IEEE The 1st International Conference on Information Science and Engineering (ICISE2009), 2009;1:5030-5032.

\section{AUTHOR BIOGRAPHIES}

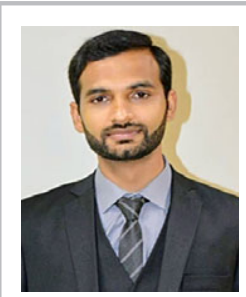

Muhammad Tayyab received the B.Sc. degree in electrical engineering from the University of the Punjab, Lahore, Pakistan, in 2012 and the M.Sc. degree in electrical engineering from the King Fahd University of Petroleum and Minerals (KFUPM), Saudi Arabia, in 2017.
$\mathrm{He}$ is currently working as a Researcher at Helsinki Research Center, Huawei Technologies Finland, since Feb 2018. During his stay at KFUPM, he was associated with King Abdullah University of Science and Technology (KAUST), Saudi Arabia, as a Visiting Student and KFUPM-KAUST joint research initiative. His research interests include RF sensor arrays design for the diagnosis of human chest diseases, RF sensor arrays design for the multiphase flow measurements in oil industry, and Mobility management in 5G. He received a Gold Medal award for obtaining first position in his B.Sc. degree.

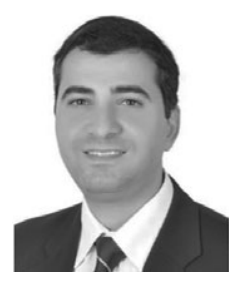

Mohammad S. Sharawi received the Ph.D. degree in RF systems engineering from Oakland University, Oakland, MI, USA, in 2006. He was a Hardware Design Engineer with Silicon Graphics Inc., Mountain View, CA, USA, from 2002 to 2003. From 2006 to 2008, He became a Faculty Member with the Computer Engineering Department, German Jordanian and Philadelphia Universities in Amman, Jordan. He was a Research Scientist with the Applied Electromagnetics and Wireless Laboratory, Oakland University, from 2008 to 2009 and in 2013. In 2014, he joined the iRadio Laboratory, University of Calgary, Calgary, AB, Canada, as a visiting research Professor until 2015. He is currently a Professor of Electrical Engineering with King Fahd University of Petroleum and Minerals (KFUPM), Dhahran, Saudi Arabia. Dr. Sharawi is the Founder and Director of the Antennas and Microwave Structure Design Laboratory (AMSDL). He is the single author of the book, Printed MIMO Antenna Engineering, Artech House, 2014. He has authored/coauthored seven book chapters in antenna design, MIMO antenna systems and RF systems, along with over 200 refereed international journal and conference paper publications mostly with the IEEE. He holds 12 issued and 14 pending patents from the US-Patent Office. His current research interests include printed multiple-input-multiple-output antenna systems, miniaturized printed antennas and antenna arrays, active integrated antennas, reconfigurable antennas, microwave circuits and electronics, millimeter-wave antennas and antenna arrays, and applied electromagnetics. Dr. Sharawi is an IET Fellow and Senior member of IEEE. He was a recipient of the prestigious Excellence in Scientific Research and Best Research Project Awards from KFUPM in 2015 and 2017. He received conference paper awards in IEEE LAPC 2014, and IEEE MeCAP 2016. He has served/serving on the technical and organizational committees of several international IEEE conferences, especially EuCAP, APS, APWC, APCAP, and ICCE. 


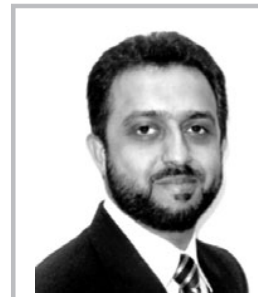

Atif Shamim received the M.A.Sc. and Ph.D. degrees in electrical engineering from Carleton University, Canada, in 2004 and 2009, respectively. He was an NSERC Alexander Graham Bell Graduate scholar at Carleton University from 2007 till 2009 and an NSERC Postdoctoral Fellow from 2009 to 2010 at King Abdullah University of Science and Technology (KAUST), KSA. In August 2010, he joined the Electrical Engineering Program at KAUST, where he is currently an Associate Professor. He was an Invited Researcher at the VTT Micromodules Research Center (Oulu, Finland) in 2006. His research interests are in integrated on-chip antennas, low power CMOS RFICs for system-on-chip (SoC) applications and advanced system-on-package (SoP) designs in multilayer LTCC, LCP, and paper through screen and inkjet printing techniques. Dr. Shamim was the recipient of the Best Paper Prize at the EuWiT Conference in the EuMA week (2008). He was given the Ottawa Center of Research Innovation (OCRI) Researcher of the Year Award (2008). His work on Wireless Dosimeter won the ITAC SMC Award at Canadian Microelectronics Corporation TEXPO (2007). He received the Best Student Paper Finalist Prize at IEEE APS Conference in 2005.

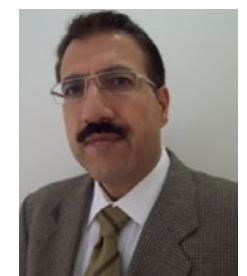

Abdelsalam Al-Sarkhi is currently a professor and Fluid laboratory director at King Fahd University of Petroleum and Minerals (KFUPM), Saudi Arabia. He holds a B.S., MS, and Ph.D degree in Mechanical Engineering. Before joining KFUPM he was a research associate in the Tulsa University Fluid Flow Project at the University of Tulsa, Ok, USA. During summers 2010-2017, Dr. Al-sarkhi was a visiting research professor and consultant at the department of petroleum engineering at Tulsa University working on a project in multiphase flow area. He was an assistant and associate professor and chairman of Mechanical Engineering Department at Hashemite University, Jordan from 2001 to 2006. He also worked as a research associate at University of Illinois Urbana-Champaign with Prof. T.J. Hanratty multiphase flow group from 1999 to 2001. He conducted funded research by US National Science Foundation (NSF) and US Department of Energy in the area of multiphase flow with Drag Reducing Polymers. Dr. AL-sarkhi conducted several consultations for major oil and gas companies like Schlumberger, Chevron and Saudi Aramco. He conducted research in multiphase flow area since 1999; he has been the principle investigator on many research projects in the United States, Jordan, and Saudi Arabia. $\mathrm{He}$ is an author of over 75 refereed journal publications and over 35 publications in international conferences. These papers have been ground breaking in the area of multiphase flow in pipes.

How to cite this article: Tayyab M, Sharawi MS, Shamim A, Al-Sarkhi A. A low complexity RF based sensor array for lung disease detection using inkjet printing. Int J RF Microw Comput Aided Eng. 2018; e21586. https://doi.org/10.1002/mmce.21586 